\title{
A new species of Tekellina (Araneae, Araneoidea) from the Russian Far East
}

\author{
Yuri M. Marusik \& Mikhail M. Omelko
}

\begin{abstract}
Marusik, Y. M. \& Omelko, M. M. 2017: A new species of Tekellina (Araneae, Araneoidea) from the Russian Far East. — Entomol. Fennica 28: 164-168.

A new species, Tekellina yoshidai $\mathbf{s p .} \mathbf{n}$., is described based on the holotype female from the Maritime Province of Russia. It is the first record of the genus in Russia and the northernmost record in the entire range. The new species is most similar to T. sadamotoi Yoshida \& Ogata, 2016 from Japan. Figures are provided for both species. The male palp of T. sadamotoi was studied with a SEM. It was found that palpal sclerites in T. sadamotoi and other Tekellina species are incorrectly homologized. Judging from the structure of the male palp and the female palpal claw, Tekellina seems to be misplaced in Theridiidae and belongs elsewhere.
\end{abstract}

Y. M. Marusik, Institute for Biological Problems of the North RAS, Portovaya Str. 18, Magadan, Russia; Zoological Museum, Biodiversity Unit, FI-20014 University of Turku, Finland; Department of Zoology \& Entomology, University of the Free State, Bloemfontein 9300, South Africa; E-mail: yurmar@mail.ru M. M. Omelko, Far Eastern Federal University, Sukhanova 8, Vladivostok 690950, Russia; Federal Scientific Center of the East Asia Terrestrial Biodiversity FEB RAS, 690022 Vladivostok, Russia; E-mail: omelkom@gmail.com

Received 20 April 2017, accepted 11 May 2017

\section{Introduction}

Tekellina Levi, 1957 is a small genus of araneoid spiders with eight named species (World Spider Catalog 2017) that are currently placed in Theridiidae. The genus has a rather unusual geographic distribution: Florida (1 species), Brazil (5), China (1) and Japan (1). All species are well illustrated, but Tekellina has never been revised, and the species from different biogeographical realms have never been compared with one another. Judging from the shape of the copulatory organs (i.e. medio-lateral or even basal but not anterior position of "paracymbium" with a pit or furrow in "paracymbium", lack of copulatory ducts in Asian and two Brazilian species, etc.) and the distribution, the genus is most likely not monophyletic, and at least some species may not belong to Theridiidae.

While studying spiders from the Russian Far East we faced difficulties identifying a small, theridiid-like spider with an epigyne resembling Howaia Lehtinen \& Saaristo, 1980, a genus belonging to Nesticidae. A recent publication by Yoshida and Ogata (2016) with a well-illustrated Tekellina sadamotoi Yoshida et Ogata, 2016 allowed us to identify our specimen as Tekellina sensu lato, a genus previously unknown in Russia. Comparison of the epigyne of our specimen to the figures in Yoshida and Ogata (2016) led us to conclude that we have an undescribed species, the description of which is given below. 


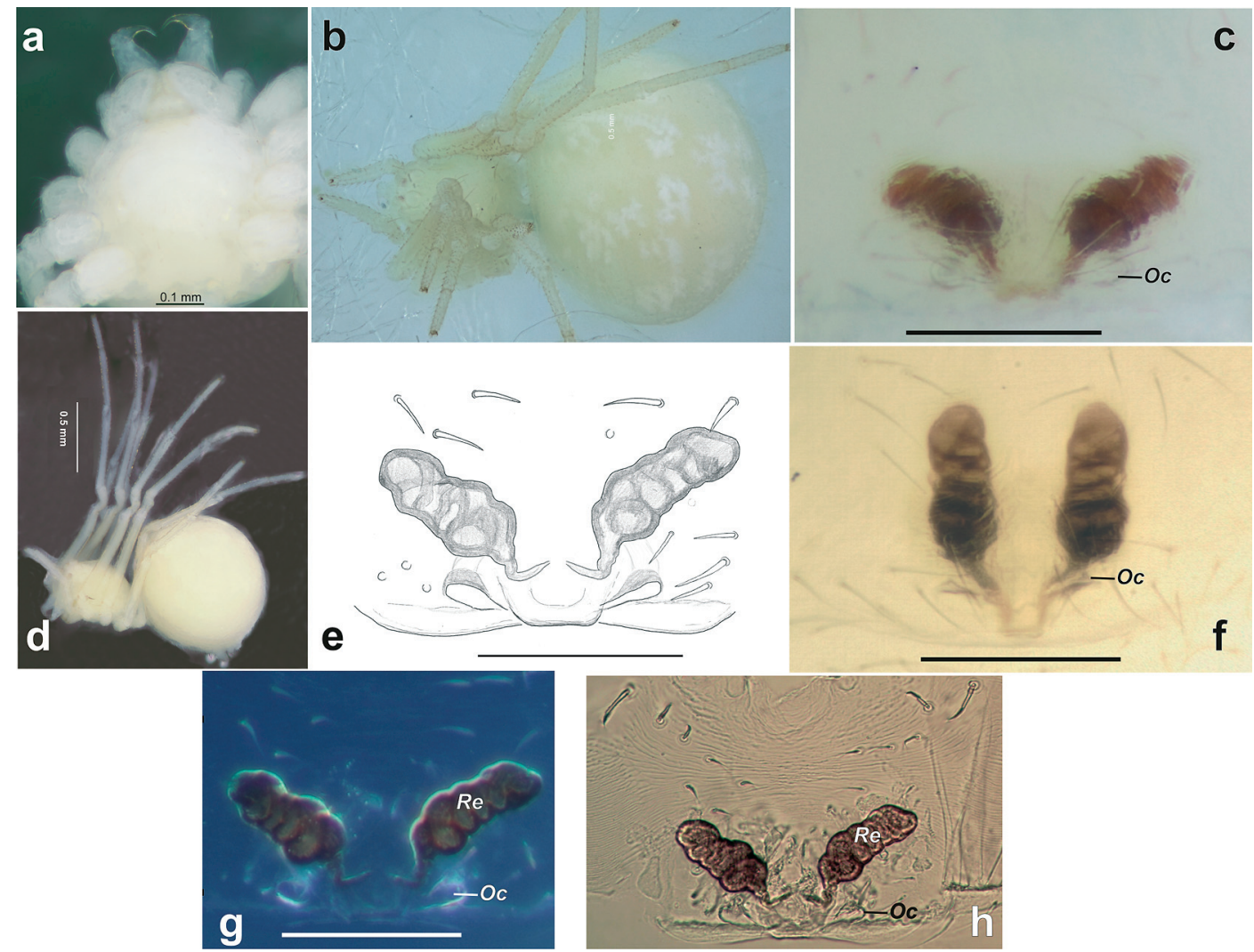

Fig. 1. Habitus and epigyne of Tekellina yoshidai sp. n. (a-e, g-h) and T. sadatamoi (f). - a. Prosoma, ventral, showing toothless chelicera and shape of sternum and mouthparts. - b. Habitus, dorsal. - c, f. Intact epigyne, ventral. - d. Habitus, lateral. $-\mathrm{e}, \mathrm{g}$, h. Macerated epigyne, ventral. Scale $=0.1 \mathrm{~mm}$ if not otherwise indicated. Abbreviations: $R e$, receptacle; Oc, copulatory opening.

\section{Materials and methods}

Specimens were photographed with a Canon EOS 7D camera attached to an Olympus SZX16 stereomicroscope, Pro-Microscan camera attached to the Olympus BH-2 and with a SEM JEOL JSM-5200 scanning microscope at the Zoological Museum, University of Turku, Finland. Digital images were montaged using CombineZP and Helicon focus 3.10 image stacking software. Epigynes were cleared in a $\mathrm{KOH} /$ water solution until soft tissues were dissolved.

Standard abbreviations are used for leg segments: Fe femur, $\mathrm{Pa}$ patella, $\mathrm{Ti}$ tibia, Mt metatarsus, Ta tarsus. The measurements are in $\mathrm{mm}$. The holotype and comparative material will be deposited in the Zoological Museum of Moscow State University (ZMMU).

\section{Taxonomy}

\subsection{Description of Tekellina yoshidai sp. $\mathrm{n}$.} (Figs 1a-e, g-h, 2e-f, 3)

Type material. Holotype $q$ (ZMMU), Russia, Maritime Prov., some $30 \mathrm{~km}$ E of Ussuriysk, Kamenushka Vill., $43^{\circ} 36.45^{\prime} \mathrm{N} 132^{\circ} 13.60^{\prime} \mathrm{E}$, 29.VIII.2001, Y. M. Marusik leg.

Diagnosis. The new species is most similar to T. sadamotoi, from which it can be distinguished by its large size (carapace 0.57 long vs 0.45 ) and the shape of the epigyne. The receptacles of $T$. yoshidai sp. n. are strongly divergent (Fig. 1c, e, g-h) vs. parallel in T. sadamotoi (Fig. 1f). Tekellina yoshidai $\mathbf{s p . ~ n . ~ i s ~ w e l l ~ d i f f e r e n t i a t e d ~ f r o m ~}$ another Asian congener, T. helixicis $\mathrm{Gao}$ et $\mathrm{Li}$, 2014, by having much shorter receptacles with 


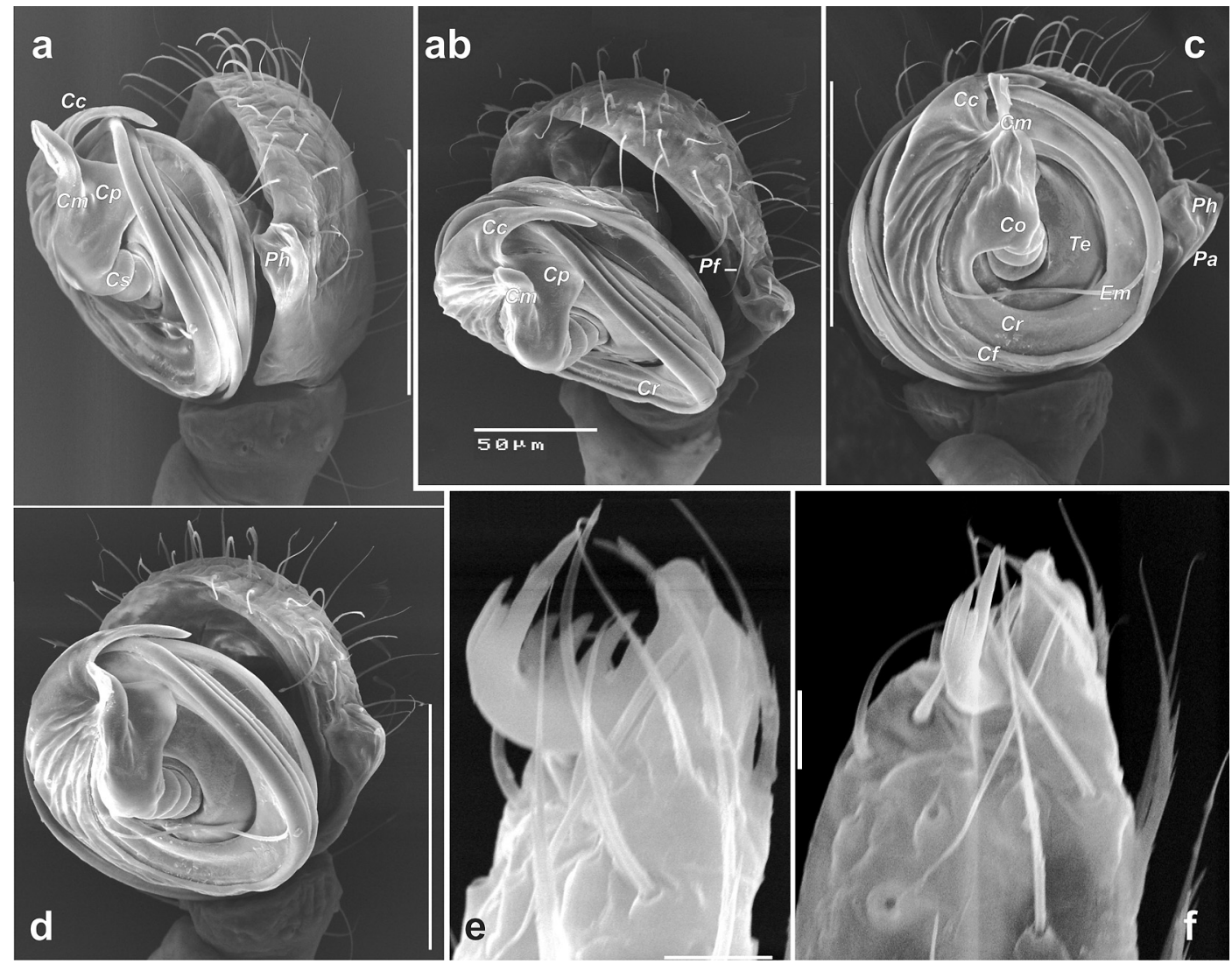

Fig. 2. Male palp of Tekellina sadatamoi (a-d) and female palp of T. yoshidai sp. n. (e-f). - a. Male palp, retrolateral. - b, c. Same, anterior and ventral. - d. Same, antero-ventral. - e, f. Palpal tarsus, lateral and dorsal. Scale $=0.1 \mathrm{~mm}$ if not otherwise indicated. Abbreviations: $\mathrm{Cc}$, terminal claw like arm; $\mathrm{Cm}$, mesal arm; $\mathrm{Co}$, conductor; $C p$, plate-like arm; $C r$, coiled ribbon shaped arm; $C s$, stem of conductor; $E m$, embolus; $P a$, paracymbium; $\mathrm{Ph}$, paracymbium hollow; $\mathrm{Te}$, tegulum.

fewer loops (about 20 in T. helixicis, $c f$. figs 71c,d, 73a,b in Gao et Li 2014).

Description. Female. Total length 1.5. Carapace 0.57 long, 0.45 wide, whitish, pale, without pattern. Chelicerae toothless (Fig. 1a). Claws on legs and palps dark, distinct on the background of whitish, pale legs. Palpal claw bent, uniseriate, with 7 teeth, 6 teeth lateral and 1 dorsal (Fig. 2ef). Leg and palp measurements in Table 1. Abdomen wider (1.14) and higher (1.0) than long (0.94), with almost indistinct pattern, composed of white guanine spots. Epigyne as in Fig. 1c, e, g-h: Copulatory openings $(O c)$ slit like, separated by more than their length. Receptacles $(R e)$ easily visible through integument, heavily sclerotized, about 3 times longer than wide, strongly divergent, twisted around axis and forming about 4 coils.
Etymology. The species is named after the late Hajime Yoshida (Yamagata, Japan) for his great contribution in the study of East Asian Theridiidae.

Distribution. Type locality only (Fig. 3).

\subsection{Description of the male palp} of Tekellina sadamotoi Yoshida et Ogata, 2016 (Figs 1f, 2a-d, 3a)

Tekellina sadamotoi Yoshida \& Ogata, 2016: 15, f. $1-13($ ぷ우).

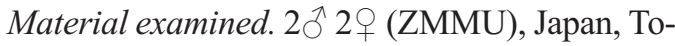
kyo, Musasashi-murrayama-shi, Kishi, 26.XII. 2016, Takeaki Ichikawa leg.

Diagnosis. See the diagnosis for T. yoshidai sp. $n$. 
Table 1. Leg and palp measurements (mm) of Tekellina yoshidai sp. n. (holotype female). Abbreviations: Fe, femur; Pa+Ti, patella + tibia; Mt, metatarsus; Ta, tarsus.

\begin{tabular}{llllll}
\hline & $\mathrm{Fe}$ & $\mathrm{Pa}+\mathrm{Ti}$ & $\mathrm{Mt}$ & $\mathrm{Ta}$ & Total \\
\hline Palp & 0.2 & 0.19 & & 0.19 & 0.58 \\
I & 0.73 & 0.71 & 0.39 & 0.24 & 2.07 \\
II & 0.73 & 0.71 & 0.39 & 0.25 & 2.08 \\
III & 0.64 & 0.43 & 0.31 & 0.24 & 1.62 \\
IV & 0.73 & 0.64 & 0.36 & 0.24 & 1.97 \\
\hline
\end{tabular}

Description. Described by Yoshida and Ogata (2016). Here we provide a description of the male palp examined with a scanning electron microscope. Male palp as in Fig. 2a-d, with an almost round cymbium; cymbium with semicircular paracymbium $(\mathrm{Pa})$ in mid part of retrolateral margin, paracymbium with shallow hollow $(P h)$ and prolateral furrow $(P f)$; bulb discoid, ventral part of tegulum flat, most of tegular $(\mathrm{Te})$ surface covered with coiled ribbon-shaped conductor $(\mathrm{Co})$ originating from centre of tegulum; stem of conductor $(C s)$ corkscrew in shape, with at least 3 loops; conductor with 4 arms: coiled ribbonshaped arm $(\mathrm{Cr})$ directed counter-clockwise, terminal claw like arm $(C c)$ directed clockwise, mesal arm $(\mathrm{Cm})$ directed ventro-anteriorly, and a plate like arm $(C p)$ lying on the ribbon-shaped arm; embolus (Em) filamentous, coiling several times, hidden by fold of conductor $(C f)$; fold of conductor serves as a sheath.

Distribution. Known only from Japan (Fig. 3a).

Note. In addition to the description of the male palp, Fig. 1f of the female epigyne is provided for comparison with T. yoshidai $\mathbf{s p .} \mathbf{n}$.

\section{Discussion}

There are certain doubts whether Tekellina, even its type species T. archboldi Levi, 1957 from Florida, belongs to Theridiidae. Tekellina species lack cheliceral teeth, a character known only in Latrodectus and Hadrotarsinae (see Agnarsson

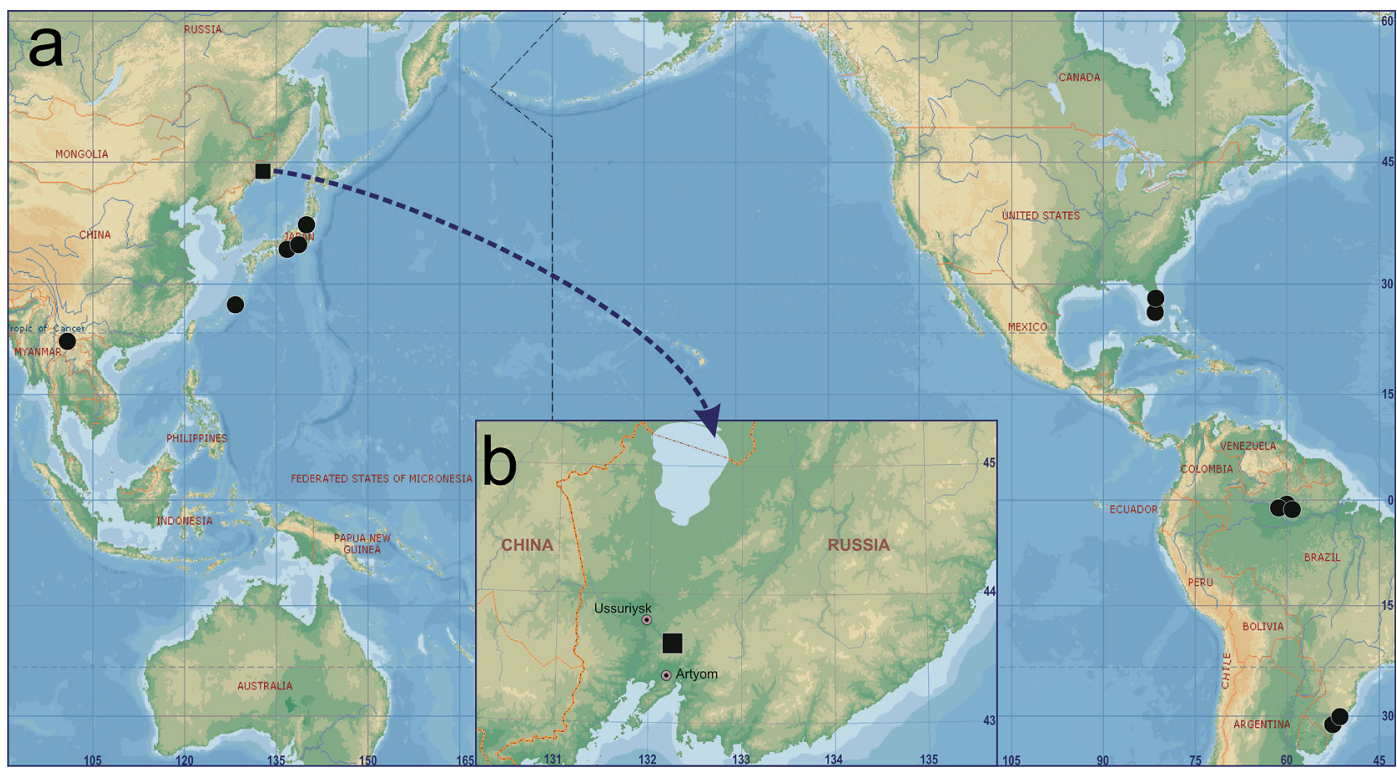

Fig. 3. - a. Distribution records of Tekellina species. - b. Type locality of $T$. yoshidai sp. $\mathbf{n}$. 
2004), have the "paracymbium" located medially (Fig. 2a-d) or even basally, but not anteriorly as in all Theridiidae. Additionally, the "paracymbium" has a pit (cf. fig. 7 in Levi 1957 and figs 1, 7, 9, 13 in Marques \& Buckup 1993) or furrow (Fig. 2b).

It appears that the palpal sclerites in Tekellina have been incorrectly homologized due to its very small size. The present study of the male palp of $T$. sadatamoi by SEM microscopy revealed that the sclerites previously designated as the embolus (E), conductor (C) and theridiid tegular apophysis are in fact three different arms of the conductor: ribbon-shaped arm $(\mathrm{Cr})$, mesal $\operatorname{arm}(\mathrm{Cm})$ and claw like arm $(C c)$. Levi (1957) indicated a palpal radix (R) and median apophysis (M) on $T$. archboldi, which we refer to as the mesal arm $(\mathrm{Cm})$ and ribbon-shaped arm $(\mathrm{Cr})$, respectively.

The three Asian Tekellina species, including the one described here, have the receptacles twisted about the axis and lack tube like sclerotized copulatory ducts that are well separated from the receptacles, a conformation known in the two New World species (cf. fig. 11 in Levi 1957 and figs 11-12 in Marques and Buckup 1993).

The shape of the conductor in the Asian Tekellina species is similar to that in Nesticiellini (Nesticidae), and particularly Hamus Ballarin et Li, 2015 and Nescina Ballarin et Li, 2015 (see Lin et al. 2016). Nesticellini also have a conductor with three arms, but the ribbon-shaped arm (or prolateral arm) is much shorter than in Tekellina and the embolus is not hidden by the conductor. Although the two groups are similar in the shape of the conductor, other characters are very different. Nesticidae have an elongated paracymbium at the base of the cymbium with at least two processes (not elongated, not basal, and no processes of paracymbium in Tekellina Fig. 2a-d), strong, and almost straight and symmetrical palpal claw in the female (bent and asymmetrical in Tekellina, Fig. 2e-f). In Nesticidae, the epigyne has a me- dian plate, which is lacking in Tekellina (Figs 1ch).

Currently, we cannot clarify the position of Tekellina among other Araneoidea, but only doubt its position within any described subfamilies of Theridiidae.

Acknowledgements. We thank Sergei Y. Storozhenko (Vladivostok, Russia) for arranging the trip to Kamenushka Village where the new species was collected. We are grateful to Akio Tanikawa (Tokyo, Japan) and Takeaki Ichikawa (Tokyo, Japan) who supplied us with T. sadatamoi. Special thanks to Seppo Koponen, who arranged our stay in Turku and provided working facilities in the Zoological Museum. English of the final draft was kindly checked by Sarah Crews (Californian Academy of Sciences, San Francisco, USA). This project was supported in part by the Far Eastern Federal University and a grant from the President of the Russian Federation (MK-6046. 2016.4).

\section{References}

Agnarsson, I. 2004: Morphological phylogeny of cobweb spiders and their relatives (Araneae, Araneoidea, Theridiidae). - Zoological Journal of the Linnean Society $141: 447-626$.

Gao, C. X. \& Li, S. Q. 2014: Comb-footed spiders (Araneae: Theridiidae) in the tropical rainforest of Xishuangbanna, Southwest China. - Zoological Systematics 39(1): 1-135.

Levi, H. W. 1957: The North American spider genera $\mathrm{Pa}$ ratheridula, Tekellina, Pholcomma and Archerius (Araneae: Theridiidae). - Transactions of the American Microscopical Society 76: 105-115.

Lin, Y. C., Ballarin, F. \& Li, S. Q. 2016: A survey of the spider family Nesticidae (Arachnida, Araneae) in Asia and Madagascar, with the description of forty-three new species. - ZooKeys 627: 1-168.

Marques, M. A. L. \& Buckup, E. H. 1993: Novas espécies de Tekellina do Brasil (Araneae, Theridiidae). - Iheringia (Zool.) 74: 125-132.

Yoshida, H. \& Ogata, K. 2016: A new species of the newly recorded genus Tekellina (Araneae: Theridiidae) from Japan. - Acta Arachnologica 65(1): 15-18.

World Spider Catalog 2017: World Spider Catalog, version 18.0. Natural History Museum Bern. URL http://wsc. nmbe.ch (Site visited on 11 April 2017). 